\title{
Equity Risk Factors for a Small Open Economy: A Risk Management Perspective
}

\author{
Hossein Asgharian \\ Lund University, Sweden \\ Björn Hansson \\ Lund University, Sweden
}

This article seeks to find factors that can account for the determinants of common variations in returns for a small open economy where the Swedish stock market serves as an example. The importance of the candidate factors is first analyzed by looking at the standard deviation of their mimicking portfolio returns, while their performance is evaluated from a risk management viewpoint. The results of the volatility analysis verify that the market, as represented by both the world market portfolio and the Swedish home market portfolio, is a crucial factor and most of the macro factors seem to be redundant. The results of the risk management exercise show that the market factor and the portfolios mimicking size and book-to-market ratio are important (JEL G310).

Keywords: multifactor models, open economy, return covariance, risk management.

\section{Introduction}

The endeavor to find the factors driving the return generating process of stocks has a long history. Most researchers believe that macroeconomic factors should play an important role in driving return (see Chen, Roll, and Ross [1986]), but there is also a place for firm characteristics like size and price-earnings ratio (see Fama and French [1992, 1993], Daniel and Titman [1997]). This research has been important for equilibrium pricing as well as for risk management. The practical use of the factor models lies in particular for controlling

${ }^{*}$ We are grateful for the funding from The Bank of Sweden Tercentenary Foundation.

(Multinational Finance Journal, 2001, vol. 5, no. 4, pp. 225-257)

CMultinational Finance Society, a nonprofit corporation. All rights reserved.

DOI: $10.17578 / 5-4-1$ 
portfolio risk (see Burmeister et al. [1997], Chan, Karceski, and Lakonishok [1999a]) or for following a specific investment style (see Chan, Karceski, and Lakonishok [1999b]). From a risk management perspective the focus is on return volatility and covariances of returns and not on their means.

The overall purpose is to find a parsimonious set of factors that can capture the systematic components of stock return variations in a small open economy; the Swedish stock market during the period 1980 to 1997 serves as an example. A risk management perspective is the guiding principle for evaluating the importance of the factors.

The Stockholm Stock Exchange (StSE) was founded as early as 1863 , but trading was thin until the early 1900 . The StSE is a small stock market compared with giants as NYSE, TSE or LSE. Its capitalization value was SEK 2164 billion ( $\$ 270$ billion) at the end of 1997 and the average daily volume SEK 5404 million ( $\$ 680$ million). ${ }^{1}$ Besides being rather small, the StSE has some salient features. It is the domestic base for a number of relatively large multinational companies, which represent a large proportion of the market capitalization and trading value. The big firms are almost always very export oriented and Sweden is rarely the main market for these companies. The export orientation implies that there is an exchange rate risk, which leads us to believe that the variations in the net cash flows of Swedish multinationals are larger than for U.S. firms. Furthermore, there were very few public utilities and retail companies on the StSE during this period.

Existing multifactor equilibrium models give some direction to the possible set of critical factors and the chosen factors or variables have existed in several earlier models. But variables are added that are important for an economy where most industrial sectors are exposed to foreign competition and where the stock market is at least partially integrated with the world market. This is obviously important for an open economy like the Swedish one where most firms are active on export markets and some of them even on a global scale. Following Chan, Karceski, and Lakonishok (1998) the variables are divided into four categories: market (a value weighted index of the Swedish Stock Exchange and the Morgan Stanley world index), fundamental (firm characteristics like book-to-market), technical (momentum strategies) and macroeconomic. Some of the variables, like book-to-market and

1. We use the exchange rate at the end of 1997, which was 7.93 SEK per U.S. dollar. 
size, are supposedly related to priced risk factors (Fama and French [1992]), while other factors are just assumed to explain covariation among returns.

Following the famous paper by Fama and French (1993), it is now common to employ their technique of factor mimicking portfolios, which means that a portfolio of assets is constructed in such a way as to "mimic" a background factor. This design has the advantage compared to directly using the value of a background factor that is not a return, since a mimicking portfolio can be treated in the same way as a portfolio of assets. In addition, some factors are not observable but the stock sensitivities to these factors may be mirrored by firm characteristics that can be used to construct mimicking portfolios. Therefore, this paper employs factor mimicking portfolios that imitates the behavior of the underlying risk factors instead of using the variables themselves.

The analysis is divided in two parts: a basic evaluation of the factors using their mimicking portfolio volatility and an evaluation within a risk management perspective. The first part is an analysis of the importance of the candidate factors by looking at the standard deviation of the mimicking portfolio return. The intuitive idea is that if a mimicking portfolio has a large return volatility this is compatible with the underlying factor providing an essential shared element of return activity. The mimicking portfolio volatility is compared to the volatility of a benchmark portfolio that reflects idiosyncratic risk. In the second part, the performance of the different factor models is evaluated from a risk management viewpoint. In the first place the predictions of the different covariance estimators are assessed in relation to the realized values. Secondly, the estimators are compared based on the out-of-sample variances of their implied global minimum variance portfolios. Since this analysis gives such dominant role to the market portfolio a test that is more apt to measure the additive effect of the non-market factors is implemented: the tracking error volatility where the market portfolio is the target. In addition to the evaluations above, which have been used by Chan, Karceski, and Lakonishok (1999a), this paper uses Value-atRisk $(V a R)$. VaR has become a very common technique for predicting future losses and the forecasted future portfolio variance is an important input in most $V a R$ models. Each estimator of the variance covariance matrix is used to compute its related VaR models. These models are then judged using the ex post distribution of the portfolio return.

The contribution is to give an example of factors that might be 
important for an open economy, which is valuable for research on other stock markets of open economies. The results shed light on other investigations in this area in particular Chan, Karceski, and Lakonishok (1998 and 1999a). Finally, this is the first analysis of the Swedish stock market using mimicking portfolios within risk management.

The results in the first part verify that the market, which consists of the world market portfolio and the Swedish market portfolio, is a crucial factor for explaining the return covariation and that most of the macro factors, including the foreign exchange factor, seem to be inessential. In the second part, a pure forecasting exercise highlights once again the importance of the market factor. However, it is interesting to find that in the analysis of the different global minimum variance portfolios, which is a problem more analogous to practical risk management, not only the market portfolio but also portfolios mimicking size and book to market are important.

The outline of the paper is as follows: section II discusses the data, the definition of the factors, the methods for the construction of the factor mimicking portfolios and the estimation of the covariance matrices of the factor models; section III analyzes the empirical results and there is finally a conclusion in section IV.

\section{Data and Method}

\section{A. Data}

The data cover the period 1977 to 1997 and consist of monthly Swedish stock returns that are corrected for dividends and capital changes like splits etc. For firm characteristics the article uses data from 1979-1996. The data are collected from the database "Trust". The sample includes all shares excluding banks and financial firms on the so-called "A1listan". ${ }^{2}$ The sample represents more than $95 \%$ of the market value of all shares. The number of firms is on average 95 per year with a maximum of 110 and a minimum of 72 . All information on accounting data is collected from the firms' annual statements and it is checked that all firms follow the same accounting standard. In addition each item from the annual reports has been checked to be comparable across all

2. This exclusion is mostly due to the facts that these firms' leverage and their accounting methods are not analogous to that of the other firms. 
the firms. The monthly data on market value of equity are collected from "Veckans Affärer". Data for macroeconomic variables are from the database Ecowin. The fiscal year is in December for more than $90 \%$ of the cases.

\section{B. Selected Factors}

The article generally follows Chan, Karceski, and Lakonishok (1998) to define the factors. However, a world market index and the movement in the exchange rate, which is a proxy for the relative competitive strength of the Swedish economy, are added since both factors should be important for Sweden as a small open economy with a relatively free capital market. The following four groups are used as the potential candidates for risk factors.

The market portfolio is captured by a combination of the following portfolios:

Excess returns on a value weighted index of the Swedish Stock Exchange $\left(R_{s}\right)$.

Excess returns on the Morgan Stanley world index computed in $\operatorname{SEK}\left(R_{w}\right)$.

The fundamental factors are based on the firm characteristics: ${ }^{3}$

Book-to-market ratio $(B M)$ for forming the monthly portfolios from July year $t$ to June year $t+1$ is defined by dividing the book value of the equity from the firm's last annual statement in year $t-1$ by the market value of the firm at the end of December in $t-1$.

Leverage ( $L e v$ ) is the book value of total capital divided by the book value of equity. Both figures are taken from the firm's latest annual statement in year $t-1$.

3. We follow Fama and French (1992) and use the book values from the firms' latest annual reports even if they are not from the end of December while the market values are from the end of December. It means that we, as in Fama and French (1992), assume that the changes in book values between the fiscal year end and the end of December is not substantial. Of course in a few cases it may result in incorrect values. On the other hand, using the same date for book and market value for each firm forces us to use market value from different dates for different firms. Taking into consideration that the market value is more volatile relative to the book value, this should lead to a more inaccurate estimate. 
Earnings/price ratio $(E P)$ are the earnings from the latest annual statement divided by the market value of the firm at end of December, both from $t-1$. Negative earnings/prices are excluded and the exact number varies over the years, but it is on average $11 \%$.

Size is estimated for each month as the market value of equity.

The technical factors are based on past stock returns over three nonoverlapping periods:

$R(-36,-12)$ is the return over a two-year period, beginning three years and ending one year before the start of the month under consideration.

$R(-7,-1)$ is the return over a six-month period, beginning seven months and ending one month before the start of the month under consideration.

$R(-1,0)$ is the return in the month immediately before the start of the month under consideration.

The macroeconomic factors:

Growth of the industrial production $(D I P)$ is defined as the percentage change in the monthly industrial production.

Real interest rate $(R T B)$ is the return on one-month treasury bills minus the relative changes in the monthly consumer price index $(C P I)$.

Maturity premium (Term) is the return of ten-year government bonds minus the return on one-month treasury bills.

Slope of the yield curve (Slope) is the difference between the yield on ten-year government bonds and the yield on three-month treasury bills.

Percentage change in the monthly expected inflation $(D E I)$ the expected inflation is estimated as the forecast obtained by applying an autoregressive moving average process (ARMA) to the monthly relative changes in the CPI from 1960:1 to 1998:5. 
The selected ARMA model with white noise residuals resulting from a step-wise process is:

$$
I_{t}=\sum_{i=1}^{4} \phi_{i} I_{t-i}+\phi_{12} I_{t-12}+\sum_{i=1}^{3} \theta_{i} u_{t-i}+\theta_{12} u_{t-12}+u_{t}
$$

Unanticipated inflation $(U I)$ is estimated as the forecast errors from the model above. Percentage change in the exchange rate comes from SEK/USD (DEX).

\section{Factor Mimicking Portfolios}

Factor mimicking portfolios are zero investment portfolios that are particularly sensitive to a specific factor. These portfolios are constructed according to the stock loadings on the factors: stocks with high loadings on a factor get positive weights while stocks with low loadings obtain negative weights. As a result, a portfolio with an intensified exposure to a particular factor is obtained.

\section{Estimation of Loading}

For the fundamental and the technical factors the loadings are directly represented by the corresponding variable. ${ }^{4}$ For the remaining factors the loading for each firm on each of the factors is obtained by regressing the excess stock returns on the factor using the most recent 36 months historical observations before the portfolio formation month. The estimates are updated each month. To estimate the loadings on the macroeconomic factors excess return on the world market as well as the Swedish market portfolio are included in the regression. The idea is to separate out effects that are already reflected in the market portfolios. To estimate the loadings on the home market index two alternatives are used. A univariate regression is first applied to estimate asset betas against this index. However, it is also interesting to separate the variation in stock returns due to the movements in the world market $R_{w}$ from that due to the movements only related to the home market. As an alternative $R_{w}$ is added as an explanatory variable when estimating the asset betas against the home market index.

4. For simplicity we refer to all the fundamental and technical variables as loadings since the values of the fundamental and technical variables are also supposed to represent the relative loadings of the assets on some background factors. 


\section{Constructing Mimicking Portfolios}

The purpose is to construct a portfolio with a mean return equal to the risk premium of a background factor and with a beta equal to one against the factor (see Cochrane, 2000). The background factor may be either a latent or an observable variable and its values are in general not returns.

Stocks are first sorted according to the loadings on a specific factor, secondly the stocks with low and high loadings are grouped in two different portfolios and finally a factor mimicking portfolio is constructed by taking a long position in the portfolio with high loadings and a short position in the portfolio with low loadings $(\mathrm{HmL})$.

There are several alternative methods to weight the stocks in the high-loading and the low-loading portfolios. The most common alternatives are either to form equally weighted portfolios (e.g. Chan, Karceski, and Lakonishok [1998]) or to form value weighted portfolios (e.g. Fama and French [1993]). These weighting methods are somewhat ad hoc. The approach is to weight the stocks by their relative distance of the loadings in order to maintain the link between the relative loadings and the weights. The weight of the asset $i$ in the portfolio with low loading on factor $k$ is computed as:

$$
w_{i k t}=1-\frac{x_{i k t}-\min _{i}\left(x_{i k t}\right)}{\max _{i}\left(x_{i k t}\right)-\min _{i}\left(x_{i k t}\right)},
$$

and for the portfolio with high loading the weight is:

$$
w_{i k t}=1-\frac{\max _{i}\left(x_{i k t}\right)-x_{i k t}}{\max _{i}\left(x_{i k t}\right)-\min _{i}\left(x_{i k t}\right)},
$$

where $w_{i k t}$ is the weight of asset $i$ in factor mimicking portfolio $k$ at time $t$ and $x_{i k t}$ is the loading of asset $i$ on factor $k$ at time $t$. The weights are then normalized in order to sum to one.

In the analysis the weights of the factor mimicking portfolios are updated every month except for $B M, L e v$, and $E P$ where the values from the end of December year $t-1$ are used to form mimicking portfolios for July year $t$ to June year $t+1$. Certain returns are considered as outliers and they are not used when constructing mimicking portfolios. 
The motivation is that a handful of observation should not excessively influence the portfolio return, since the portfolios are supposed to mirror common fundamental factors. Returns above $100 \%$, twelve observations, and returns below $-60 \%$, eight observations, are excluded. These observations are mostly from 1992.

\section{Benchmark Portfolios}

To analyze the behavior of the mimicking portfolios it is convenient to have a metric. For this purpose the assets are randomly divided into two groups and a portfolio is constructed by going long in one group and short in the other. The resulting random portfolio should have no significant loading on any factor risk and its variance should only reflect idiosyncratic risk. The number of stocks in this portfolio is the same as the number of stocks in the factor mimicking portfolios, since including more (less) stocks would decrease (increase) the idiosyncratic risk of the random portfolio compared to the mimicking portfolios. It would be difficult to compare the portfolio variances due to the factor loading if the potential idiosyncratic risk differs.

Two alternative benchmarks for the market and the macro-factors are used (see Chan, Karceski, and Lakonishok [1998]): the first is derived from a series of a uniformly distributed random variable between zero and one and the second benchmark is derived from randomly reshuffled series of the macro variables and the market returns (from each original series a new series is constructed by random selection without replacing). The loading of each asset on these new series is estimated (the random and the reshuffled series) and then the mimicking portfolios are constructed as above. As Chan, Karceski, and Lakonishok (1998) show grouping stocks with similar loading on these series is equivalent to grouping them according to the covariance between their historical returns. ${ }^{5}$ To insure the randomness of the new series this procedure is repeated 100 times and the average volatilities of the 100 mimicking portfolios are used for each new series as the benchmark volatility.

\section{E. Variance-Covariance Matrix of the Factor Model}

The factor model generating returns of the asset $i$ is given by:

5. See Chan, Karceski, and Lakonishok (1999) footnote in page 173. 


$$
\begin{gathered}
R_{i t}=\alpha_{i}+\sum_{k=1}^{K} \beta_{i k} f_{k t}+\varepsilon_{i t}, \text { for } i=1, \ldots, N, \\
E\left[\varepsilon_{t}\right]=0, \\
E\left[\varepsilon_{t} \varepsilon_{t}^{\prime}\right]=S,
\end{gathered}
$$

and $R_{i t}$ is the return in excess of the risk free rate for asset $i$ at time $t$, $f_{k t}$ is the value of the $k$ th factor, $\beta_{i k}$ measures the sensitivity of the asset $i$ for the factor $k$ and $\varepsilon_{i t}$ is an idiosyncratic asset specific error and $\varepsilon_{t}=$ $\left[\varepsilon_{1 t}, \ldots, \varepsilon_{N t}\right]^{\prime}$ is a $N \times 1$ vector of error terms with mean zero and variance-covariance matrix $S$. If the factor structure takes into account all cross covariances of the returns then the variance-covariance matrix of the residuals will be diagonal, since it is assumed that some idiosyncratic risk is never explained by the factor model. However, it is possible that idiosyncratic components exist in the return covariances and $S$ is therefore not diagonal. It is assumed that the systematic return covariation will persist over time but the idiosyncratic components are non-persistent and the best forecast of the future variance-covariance matrix is therefore:

$$
V=\beta \Omega \beta^{\prime}+D,
$$

where $D$ is a $N \times N$ diagonal matrix of the residual variances for $N$ time series regressions, $\Omega$ is a $K \times K$ variance-covariance matrix of the factors and $\beta$ is a $N \times K$ matrix of the sensitivities of the $N$ assets for the $K$ factors. Consequently the elements in matrix $V$ are:

$$
\begin{gathered}
V_{i, j}=\sum_{k=1}^{K} \sum_{l=1}^{K} \beta_{i k} \beta_{j l} \sigma_{k l}, \text { for all } i \neq j, \\
V_{i, i}=\sum_{k=1}^{K} \sum_{l=1}^{K} \beta_{i k} \beta_{i l} \sigma_{k l}+s_{i}^{2},
\end{gathered}
$$

where $s_{i, j}$ is the element in row $k$ and column $l$ of the covariance matrix of the factors, $\Omega$, and $s_{i}^{2}$ is the residual variance of the factor model for asset $i$. It follows that:

$$
\operatorname{cov}\left(R_{i}, R_{j}\right)=V_{i, j}+s_{i j}
$$




$$
\operatorname{var}\left(R_{i}\right)=V_{i, i},
$$

where $\sigma_{k, l}$ is the covariance between the residuals of the factor model for asset $i$ and $j$, which might partly consist of some idiosyncratic components and partly of some unexplained systematic covariation that is not captured by an incomplete factor model. The worse the factor model is the larger are the unexplained covariances and therefore $s_{i, j}$ will be larger in magnitude, while $V_{i, j}$ will shrink toward zero.

The article analyzes different models that are built from the groups of factors mentioned above. The following alternative models are used:

M1: Market portfolio.

M2: Fama and French's three-factor model.

M3: Market portfolio plus all the fundamental factors.

M4: Market portfolio plus all the technical factors.

M5: Market portfolio plus all the macroeconomic factors.

M6: Market portfolio plus all the fundamental, technical and macroeconomic factors.

M7: All the fundamental, technical and macroeconomic factors (no market).

M8: Random series mimicking portfolio.

Thus, the market portfolio is the starting point and then the other factors are added. The "Random series mimicking portfolio" is a bogus factor that serves as a benchmark.

A world market index, $R_{w}$, and a Swedish market index represent the market factor, which is orthogonal to the world market index. First the univariate regression of the home market index, $R_{s}$, on the world market index is estimated:

$$
R_{s t}=\gamma_{0}+\gamma_{1} R_{w t}+u_{t}
$$

Then $\gamma_{0}+u_{t}$, are used as proxies for the Swedish market movement in the multifactor model, which is denoted by $R_{s, o}$ and referred to as the orthogonal Swedish market index. The other factors are represented by their loading weighted mimicking portfolios. 


\section{Analysis}

The first part of this section analyzes the determinants of common variation in returns by looking at the volatility of the factor mimicking portfolios. The second part investigates the power of the different models to predict future covariances and their usefulness in risk management.

\section{A. Volatility of the Mimicking Portfolios}

A quick look at the correlations among the mimicking portfolios and their mean returns in table 1 shows that the series are in general uncorrelated. The factor representing the world market portfolio, $R_{w}$, is somewhat correlated with $R_{s}$ and the SEK/USD exchange rate, $D E X$. Looking at the correlation among the returns of the mimicking portfolios, (see table 2 ), it is obvious that the correlations increase in absolute values. Among the mean returns of the factor mimicking portfolios the following results are worth noting (see table 3 ). Only the $B M$ and the $R(-1,0)$ have mean returns that are significantly different from zero: positive and negative respectively. The result for $R(-1,0)$ indicates that there are negative autocorrelations in individual returns or mean reversion on a monthly basis.

The volatility of the factor mimicking portfolios is used to assess the importance of the factors in explaining return covariation. To see the

motivation behind this metric consider the following one-factor model:

$$
\begin{gathered}
R_{i t}=\alpha_{i}+\beta_{i k} f_{k t}+\varepsilon_{i t}, \text { for } i=1, \ldots, N, \\
E\left[\varepsilon_{t}\right]=0, \\
E\left[\varepsilon_{t} \varepsilon_{t}^{\prime}\right]=S .
\end{gathered}
$$

The variance of a portfolio of the assets can then be written as

$$
\begin{aligned}
\operatorname{var}\left(R_{p}\right) & =\sum_{i}^{N} \sum_{j}^{N} w_{i} w_{j} \sigma_{i j}=\sum_{i}^{N} \sum_{j}^{N} w_{i} w_{j}\left(\beta_{i} \beta_{j} \sigma_{k}^{2}+s_{i j}\right) \\
& =\sigma_{k}^{2} \sum_{i}^{N} \sum_{j}^{N} w_{i} w_{j} \beta_{i} \beta_{j}+\sum_{i}^{N} \sum_{j}^{N} w_{i} w_{j} s_{i j} .
\end{aligned}
$$




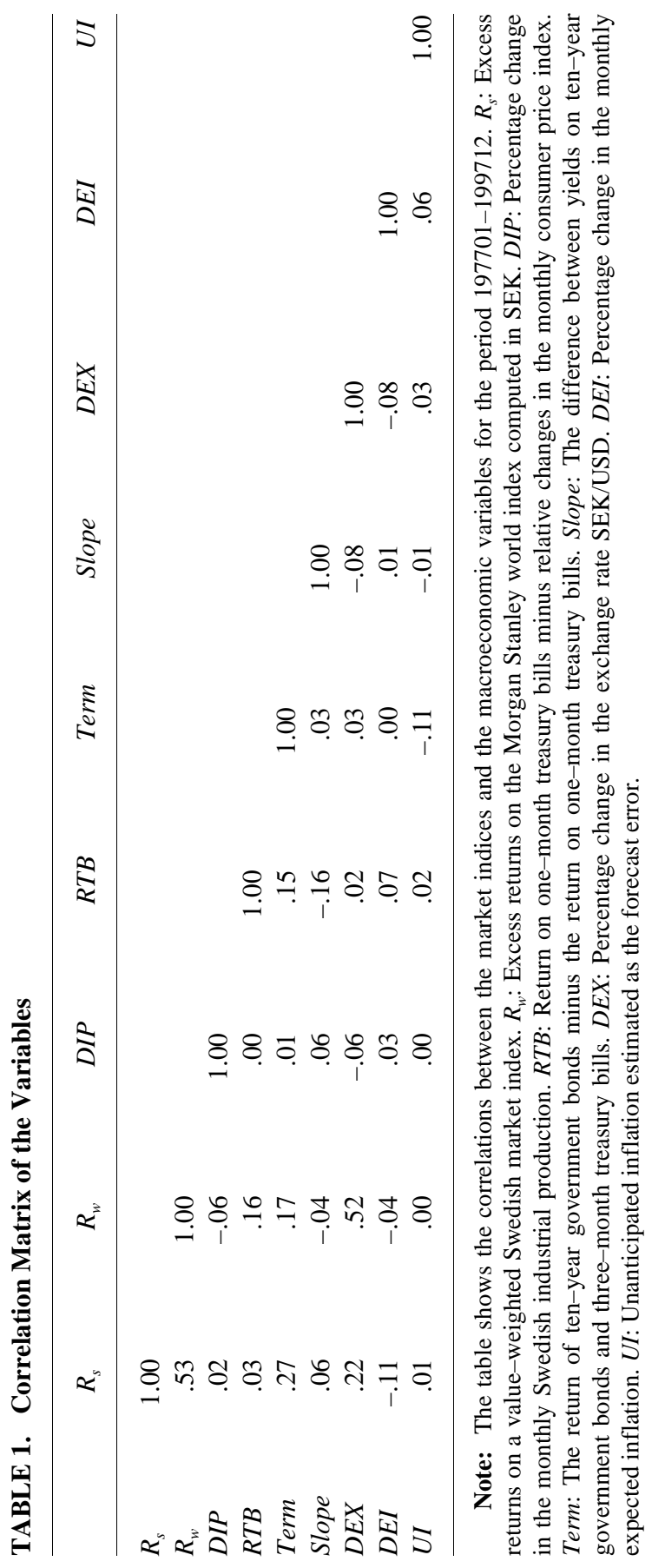




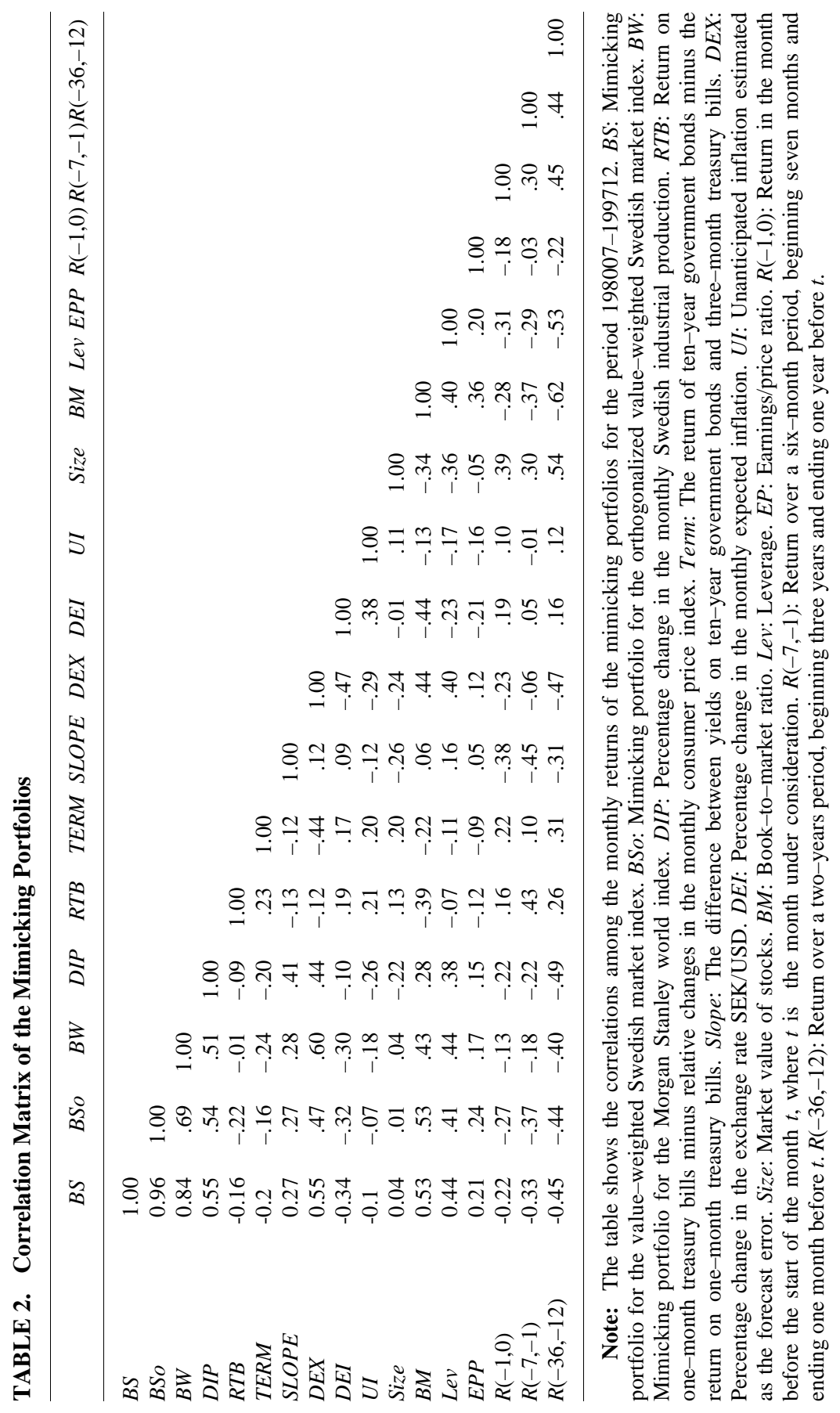


TABLE 3. Mean Returns

\begin{tabular}{lcclrc}
\hline & Std & $p$-value & & Std & $p$-value \\
\hline BS & 0.002 & .493 & UI & 0.003 & .249 \\
BSo & 0.002 & .466 & Size & 0.001 & .686 \\
$B W$ & 0 & .886 & BM & 0.008 & .014 \\
$D I P$ & 0.001 & .751 & Lev & -0.002 & .716 \\
$R T B$ & 0.001 & .619 & EPP & 0.003 & .318 \\
TERM & -0.002 & .513 & $R(-1,0)$ & -0.023 & .000 \\
SLOPE & 0.001 & .860 & $R(-7,-1)$ & 0.001 & .762 \\
DEX & 0.002 & .485 & $R(-36,-12)$ & -0.006 & .110 \\
DEI & -0.004 & .134 & & & \\
\hline
\end{tabular}

Note: The table shows the mean returns of the mimicking portfolios for the period 198007-199712. BS: Mimicking portfolio for the value-weighted Swedish market index. $B S o$ : Mimicking portfolio for the orthogonalized value-weighted Swedish market index. $B W$ : Mimicking portfolio for the Morgan Stanley world index. DIP: Percentage change in the monthly Swedish industrial production. RTB: Return on one-month treasury bills minus relative changes in the monthly consumer price index. Term: The return of ten-year government bonds minus the return on one-month treasury bills. Slope: The difference between yields on ten-year government bonds and three-month treasury bills. DEX: Percentage change in the exchange rate SEK/USD. DEI: Percentage change in the monthly expected inflation. UI: Unanticipated inflation estimated as the forecast error. Size: Market value of stocks. BM: Book-to-market ratio. Lev: Leverage. EP: Earnings/price ratio. $R(-1,0)$ : Return in the month before the start of the month $t$, where $t$ is the month under consideration. $R(-7,-1)$ : Return over a six-month period, beginning seven months and ending one month before $t . R(-36,-12)$ : Return over a two-year period, beginning three years and ending one year before $t$.

The first term is the part of the portfolio variance that is explained by the factor model while the second term is the unexplained part. For an exact factor model $\sum \sum w_{i} w_{j} s_{i j} \approx 0$, but if the factor is useless $\sigma_{k}^{2} \sum \sum w i w j \beta_{i} \beta_{j}$ $\approx 0$ since all $\beta_{i} \approx 0$. If a factor is important then assets with similar betas are correlated. A mimicking portfolio uses this to the utmost since it is constructed by going long in assets with the most positive betas and shorting assets with the lowest betas. This method maximizes the portfolio risk and it is the opposite of portfolio formation in order to reduce risk. Constructing a mimicking portfolio according to the betas against a useless or a random factor implies that the assets are partitioned on a random basis, which results in a more diversified portfolio with a lower portfolio variance. 
To analyze the standard deviations of the mimicking portfolios the article first looks at the fundamental and the technical portfolios where a random portfolio is used as a benchmark. Secondly, the article analyzes if the portfolios mimicking the market and the macro factors deviate from a portfolio based on the uniformly distributed random series. The random series benchmark is above the random portfolio (see table 4), since the former contains idiosyncratic risk as well as the covariance structure among the assets while the latter only contains idiosyncratic risk.

The standard deviations of the portfolios vary between $3.6 \%$ on a monthly basis for DEI to $6.7 \%$ for Lev (see table 4). A comparison between the standard deviations of the fundamental and technical portfolios on the one hand and the random portfolio, $1.6 \%$, on the other hand shows that the factor mimicking portfolios have at least twice the standard deviation of the random portfolio. The result of the $F$-test for equality of two variances, the variance of the mimicking portfolio versus the random portfolio, shows that the mimicking portfolios of the fundamental and technical portfolios have significantly higher variances.

The standard deviations of the market portfolios are above the standard deviation of the portfolio based on loadings on a random series. ${ }^{6}$ The market portfolios are all significantly different from the benchmark. Note, that there are no particular differences between the market mimicking portfolios whether they are orthogonalized or not. Hence, the world market portfolio does not capture the influence from the home market. The macro portfolios on the other hand have more or less the same volatility as the benchmark. The result of the $F$-test shows that it is not possible to reject the equality of the standard deviations of $R T B, T e r m, D E X, D E I$, and $U I$ with the benchmark at the 5\%-level (see table 4). In fact, DIP and Slope are only significant at the $10 \%$-level. That $D E X$, which represents foreign competition is not important may appear a bit counterintuitive since very few Swedish firms have sheltered home markets. However, the most likely explanation is that the foreign influence is mediated via the world market portfolio.

Based on these results it is possible to conclude that most of the

6. All the results from the reshuffled series are almost the same as the results of the random series. These results are not reported but available on request 
TABLE 4. Mimicking Portfolio Versus Benchmark Volatility

\begin{tabular}{lcc}
\hline & Std & $p$-value \\
\hline$B S$ & .051 & .000 \\
$B S o$ & .047 & .004 \\
$B W$ & .047 & .006 \\
$D I P$ & .043 & .076 \\
$R T B$ & .039 & .518 \\
TERM & .038 & .729 \\
SLOPE & .044 & .055 \\
$D E X$ & .041 & .233 \\
$D E I$ & .036 & .887 \\
$U I$ & .036 & .875 \\
Size & .045 & .000 \\
$B M$ & .046 & .000 \\
Lev & .067 & .000 \\
EPP & .043 & .000 \\
$R(-1,0)$ & .052 & .000 \\
$R(-7,-1)$ & .046 & .000 \\
$R(-36,-12)$ & .051 & .000 \\
Benchmark 1 & .016 & \\
Benchmark 2 & .039 & \\
\hline
\end{tabular}

Note: The table compares the standard deviations (std) of the mimicking portfolios with std of the two benchmark portfolios: a randomly constructed $H m L$ portfolio (Benchmark 1 for comparison with fundamental and technical factors) and a mimicking portfolio based on loadings on a uniformly generated random series (Benchmark 2 for comparison with market and macroeconomic factors). The table also shows the $p$-values resulting from the $F$-test of equality of two variances, which compare each mimicking portfolio against the corresponding benchmark. BS: Mimicking portfolio for the value-weighted index of the Swedish Stock Exchange. BSo: Mimicking portfolio for the orthogonalized value-weighted Swedish market index. $B W$ : Mimicking portfolio for the Morgan Stanley world index. DIP: Percentage change in the monthly Swedish industrial production. RTB: Return on one-month treasury bills minus relative changes in the monthly consumer price index. Term: The return of ten-year government bonds minus the return on one-month treasury bills. Slope: The difference between yields on ten-year government bonds and three-month treasury bills. DEX: Percentage change in the exchange rate SEK/USD. DEI: Percentage change in the monthly expected inflation. UI: Unanticipated inflation estimated as the forecast error. Size: Market value of stocks. BM: Book-to-market ratio. Lev: Leverage. EP: Earnings/price ratio. $R(-1,0)$ : Return in the month before the start of the month $t$, where $t$ is the month under consideration. $R(-7,-1)$ : Return over a six-month period, beginning seven months and ending one month before $t . R(-36,-12)$ : Return over a two-years period, beginning three years and ending one year before $t$. 
macro portfolios are redundant. ${ }^{7}$ These results are slightly stronger compared to the results of Chan, Karceski, and Lakonishok (1998) where only some of the macro portfolios were superfluous.

Although the standard deviation is used as measure for the importance of the factors there are certain doubts as to the usefulness of this metric. The magnitude of the standard deviation of a factor mimicking portfolio originates from two sources: there are large systematic differences between the asset returns with high and low loadings to this factor and/or there is a large time series variation in the factor itself (see equation 10). ${ }^{8}$ Therefore, a factor with a high variation over time will appear to be more important than a factor with a smaller variation. An example is the standard deviation of leverage versus the market where this difference is due to a few extreme observations during the turbulent years of the early 1990s when the highly leveraged firms were affected by a deep recession.

\section{B. Forecasting Variances and Covariances}

Three methods are used to judge the ability of different factor models to predict covariances: the first method compares the predicted covariances of the models with the realized covariances, the second method compares the volatility of the global minimum variance portfolio from different models and the third method analyzes the capabilities of the factor models to predict the possible future losses within a Value-atRisk framework. Notice that the whole exercise is done under the presumption that the variance-covariance is relatively stable during estimation and evaluation periods.

\section{Comparing with the Realized Covariances}

The first method compares the alternative covariance forecasts with the realized covariances estimated on 36 months future returns. ${ }^{9}$ The

7. This may be due to the fact that the market portfolio is included when we estimate the loadings on the macro variables.

8. Note that the explained part in (10) is also driven by the factor variance

9. We have also estimated realized variance-covariance matrices using 12-months future returns. This alternative results in relatively larger mean absolute errors and lower correlations with forecasted variances, compared to the case with 36-months future returns. This supports the results of Chan, Karceski, and Lakonishok (1999) that 12-months returns 
predicting powers of the factor models are compared across different models and also with two additional simple models: a full covariance matrix and a constant covariance model that is estimated as: ${ }^{10}$

$$
\operatorname{cov}_{i, j}=\overline{\operatorname{cov}}, \text { for } \forall i \neq j,
$$

where $\overline{\operatorname{cov}}$ is the average covariance. All the forecasted covariances are based on 60 months historical returns. The article uses several approaches to compare the forecasted and the realized covariances. The mean and median absolute forecast errors are used to measure the magnitude of the forecast errors. To investigate if the forecasts tend to be in the same direction as the realizations the article estimates a linear regression of the realized covariances on the forecasted covariances and also computes the correlations between the covariances. These estimations and the comparisons are repeated at the end of June each year. The reason to prefer yearly regressions to a pooled regression using all the elements of the yearly matrices is that the pooled regression results in bias since it imposes the same intercept for all the years. The intercepts will probably vary over time, since a relatively calm period is sometimes used to forecast covariances for an extreme period and it is then more likely that the forecast will on average underestimate the realized covariances, and vice versa going from a volatile period to a normal one.

Table 5 displays the summary statistics of the yearly estimated covariances. The statistics show that all models have means that are very close to each other except for the model without the market $M 7$ and the benchmark model M8. Figure 1 shows that for different factor models the yearly averages of the covariances vary over time in the same manner. For the same factor model the annual averages vary a lot over time. Note that $M 7$ explains some of the return covariation. There

give poor estimates of the variance-covariances. However, the relative powers of different models are almost the same as for the case with 36-months returns.

10. Note that the full covaring model corresponds to a $N$-factor model. The sample covariance model has no specification error, since no structure is imposed, but it may have a relatively large sampling error since a large number of parameters have to be estimated. A factor model has a smaller sampling error but is has also a specification error (see Jagannathan et al. 2000). 


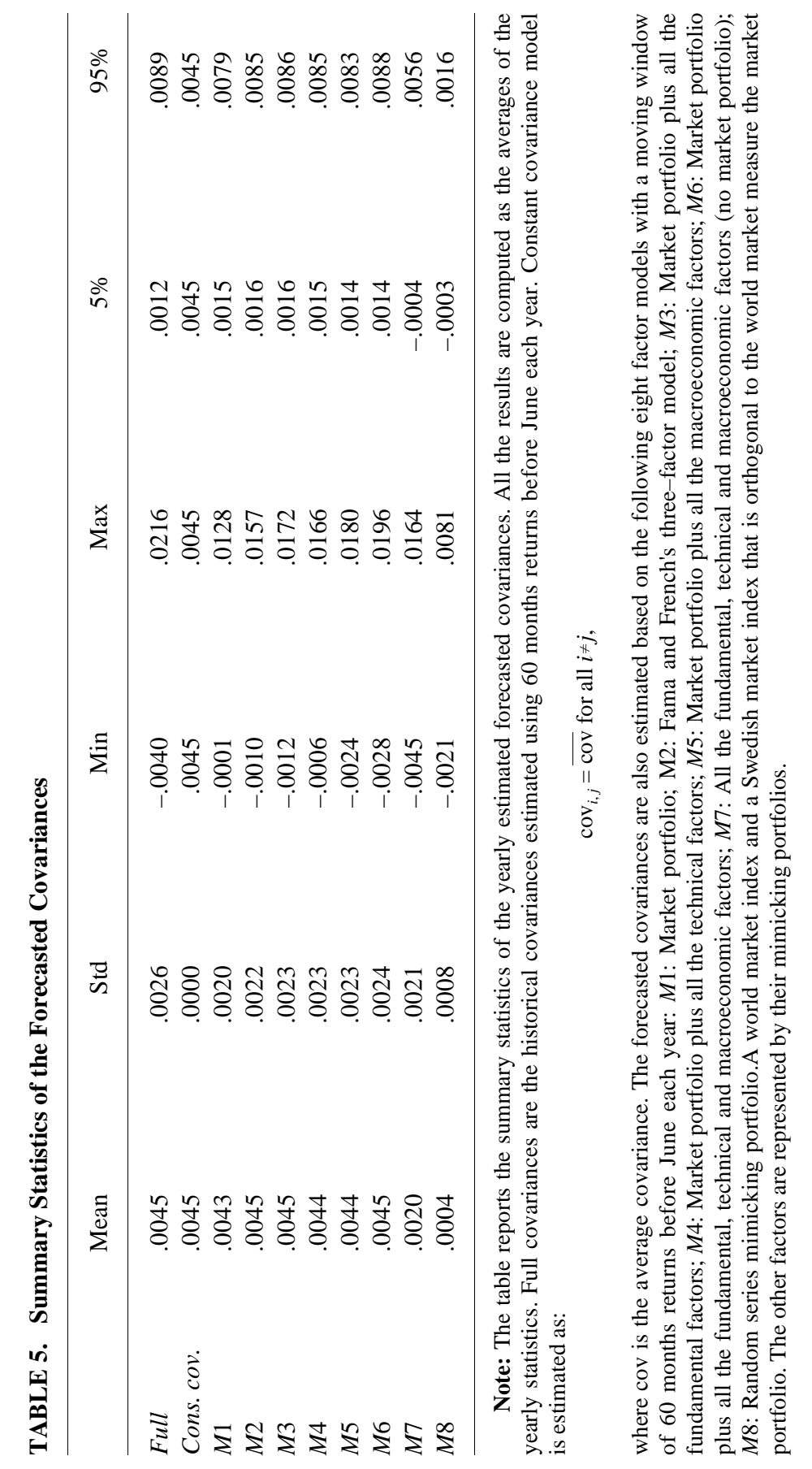




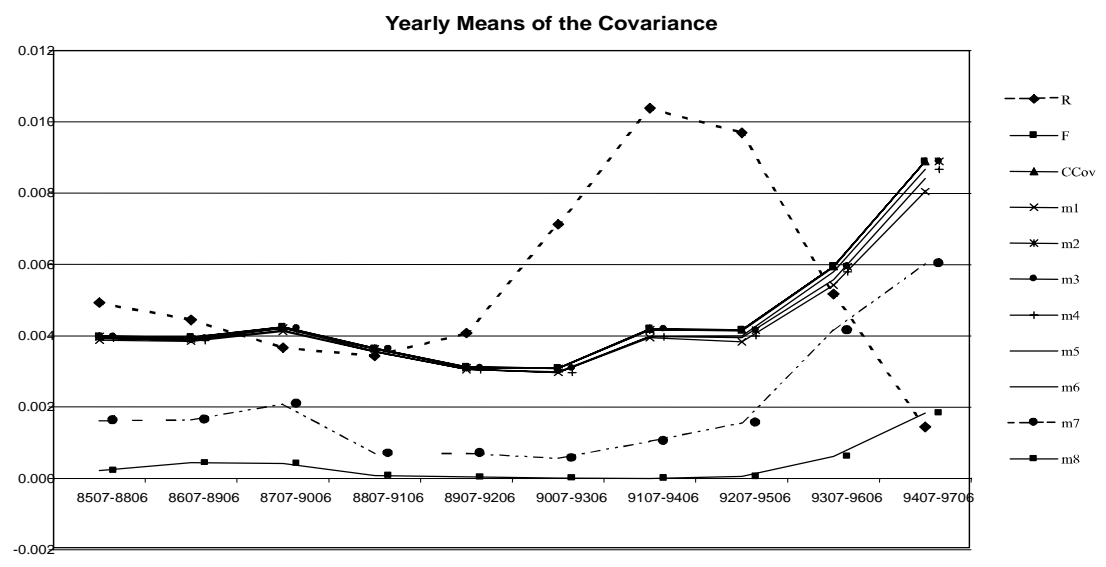

FIGURE 1.- $R$ is for realized covariance estimated based on 36 months returns after June each year. $F$ is the sample covariance estimated based on 60 months returns before June each year. CCov is estimated as the average covariances. For the definitions of the models M1-M8 see notes under the table 5. The labels of the $x$-axis show the time intervals used to estimate the realized covariances.

are very few negative entries, which can be seen from the fact that the fifth percentile is positive except for $M 7$.

Table 6 shows the statistics of the estimated absolute forecast errors and the average of the yearly estimated slopes and correlation coefficients. The main result is that the simplest factor model, $M 1$, has the smallest mean and median and its slope and correlation are more or less the same as for the more complicated models. This is similar to the results of Chan, Karceski, and Lakonishok (1999a). The model Full is almost on all scores worse than the models that include the market $M 1$ $M 6$, since it includes idiosyncratic elements and these are also reflected in its higher standard deviation in table 6. The simplest model is Constant covariance, which is not as good as $M 1$ but it does not differ that much from $M 1-M 6$. The bad scores of $M 7$ that includes all factors except the market show that the market is central for the forecast. However, these other factors are not useless since $M 7$ is definitely better than $M 8$ that stems from a bogus factor. Looking at different years in figure 2 it is interesting to notice that $M 8$, which is generally the worst model, has the smallest forecast error for the last period 9407- 


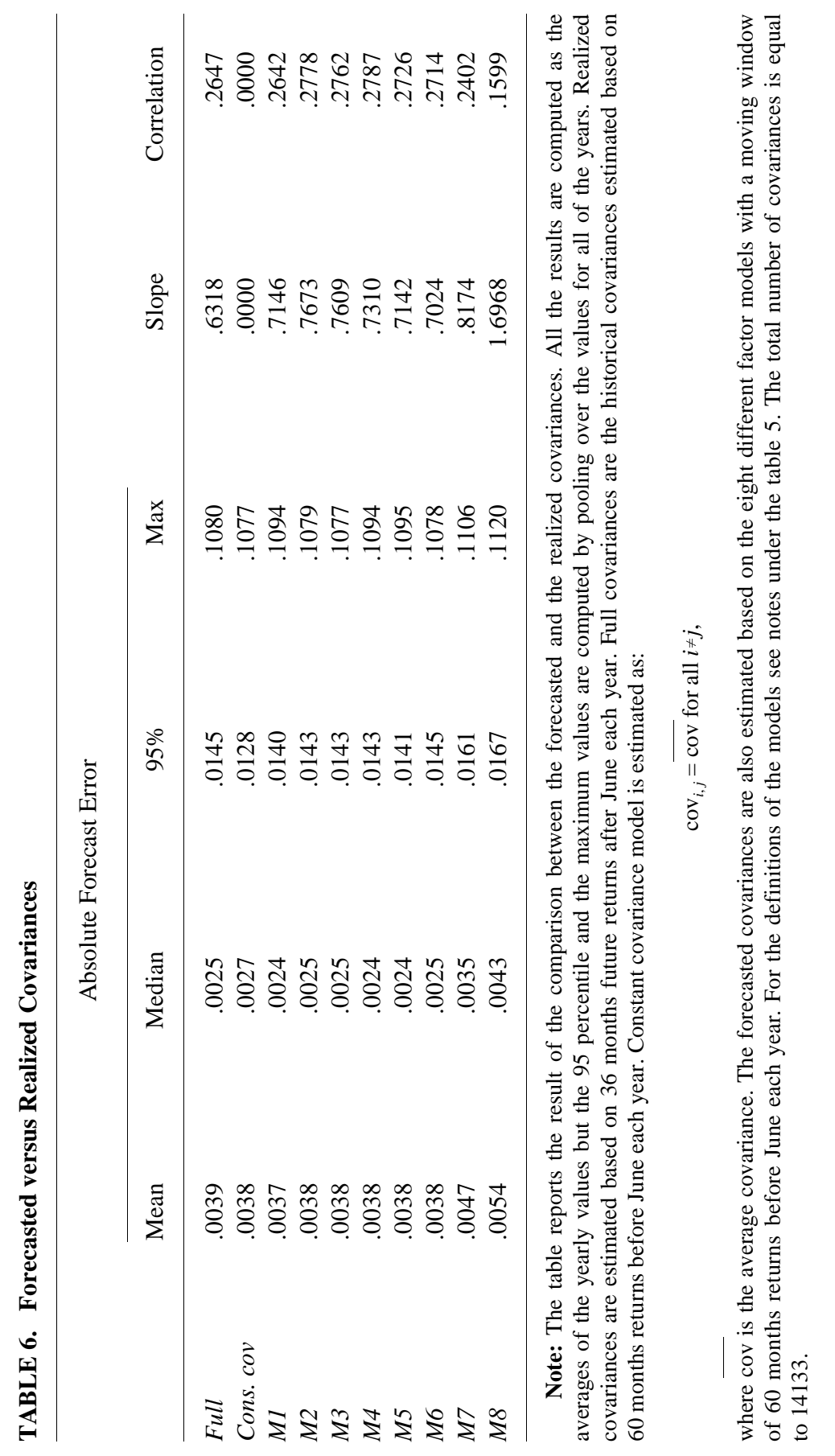




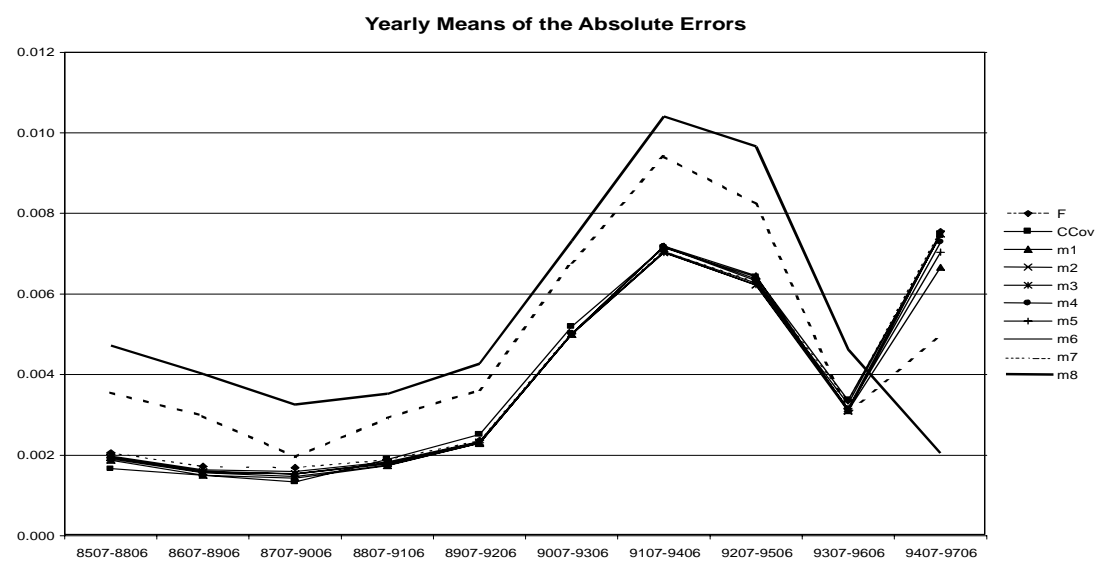

FIGURE 2. $-R$ is for realized covariance estimated based on 36 months returns after June each year. $F$ is the sample covariance estimated based on 60 months returns before June each year. CCov is estimated as the average covariances. For the definitions of the models M1-M8 see notes under the table 5. The labels of the $x$-axis show the time intervals used to estimate the realized covariances.

9706. This shows that when there is a shift from high to low market volatility, as shown by the average realized covariance, a model that generally predicts low covariances (see figure 1) will by coincidence have a small prediction error.

\section{Minimum Variance Portfolio}

This section uses alternative covariance matrices to find the global minimum variance portfolio and its corresponding weights. The alternatives are the covariance matrices given by the different factor models and the full covariance matrix. The estimated covariance matrices are based on 60 months historical returns. Short selling is not allowed and the portfolio weights are restricted to fall below $10 \%$. Portfolio weights are updated in June each year and are used for the subsequent twelve months. A value weighted portfolio and an equally weighted portfolio of all the assets included in the sample for each year are used as benchmarks. The portfolio volatility of the monthly returns is used to judge the predicting ability of the different covariance models.

Unlike the previous tests the market model $M 1$ is not any longer 
sufficient and by adding Size and BM, i.e. Fama-French three-factor model, the annual standard deviation is reduced from 0.192 to 0.183 that is a relative reduction of more than $4 \%$ (see table 7 ). Table 7 also shows the averages of the yearly values of beta, size and book-to-market for the different global minimum variance portfolios. The portfolio betas are based on the asset betas that are estimated from 60 months historical returns before the portfolio formation. The other two portfolio characteristics are computed from the average firm sizes and book-tomarket values over 60 months preceding June of each year. All the factor models, $M 1-M 7$, have low beta values. The models including size and book-to-market, $M 2-M 3$ and $M 6-M 7$, are larger in size than the equally weighted portfolio but their book-to-market values are smaller. The naive strategies of the equally or the value weighted portfolios have much higher volatility than all factor models. In general the portfolios with low volatility pick firms with low betas, low book-to-market ratios and above the average size. This is consistent with the interpretation of these attributes as risk factors.

In practice it is more common that a portfolio manager has to minimize portfolio risk relative to a target portfolio. To find the global minimum variance portfolio is the same as minimizing the tracking error volatility where the target is a risk free asset, i.e. an asset with zero sensitivities to all the factors. It is virtually impossible to find a portfolio with a zero market beta since short sales are not allowed and there are almost no assets with negative betas. As a result the optimization procedure tries to find portfolios with as low market betas as possible. To better gauge the importance of the other factors a target portfolio whose market beta is similar to the average beta is chosen. The simplest choice is the value weighted market portfolio, which has a beta equal to one, since it is simple for a portfolio to imitate. To minimize the tracking error volatility, the return of each asset in excess of the value weighted market index is computed and then the global minimum variance portfolio with the same restrictions as above is found. The result is presented in table 8 . The portfolio with the smallest tracking error is the Fama-French three-factor portfolio, $M 2$, followed by factor portfolios including these three factors $M 3, M 6$ and $M 7$. That the value weighted portfolio has a small tracking error is not surprising since this portfolio is almost identical to the target portfolio: the difference is that the target contains all existing assets in the month under consideration while the 


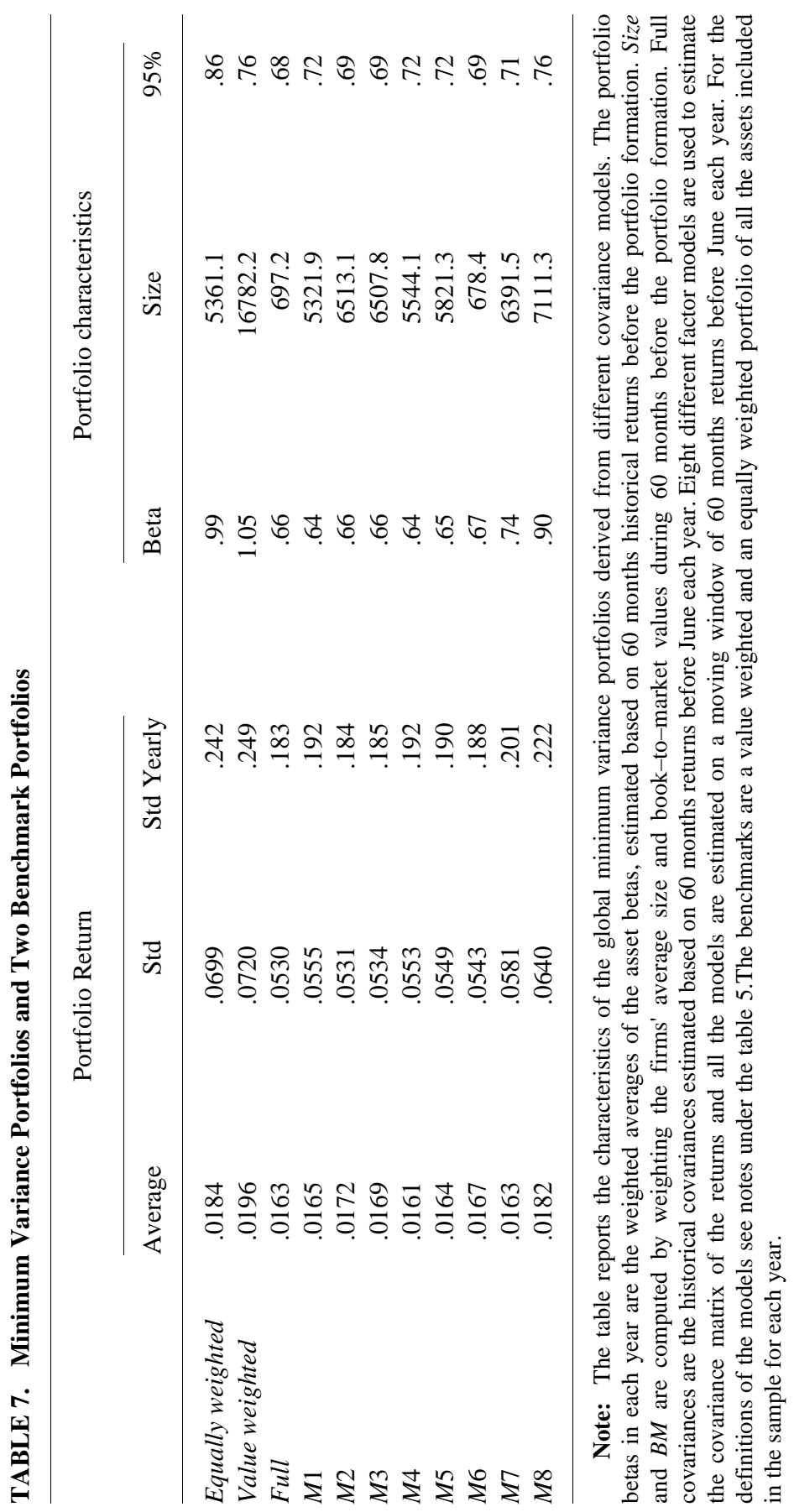




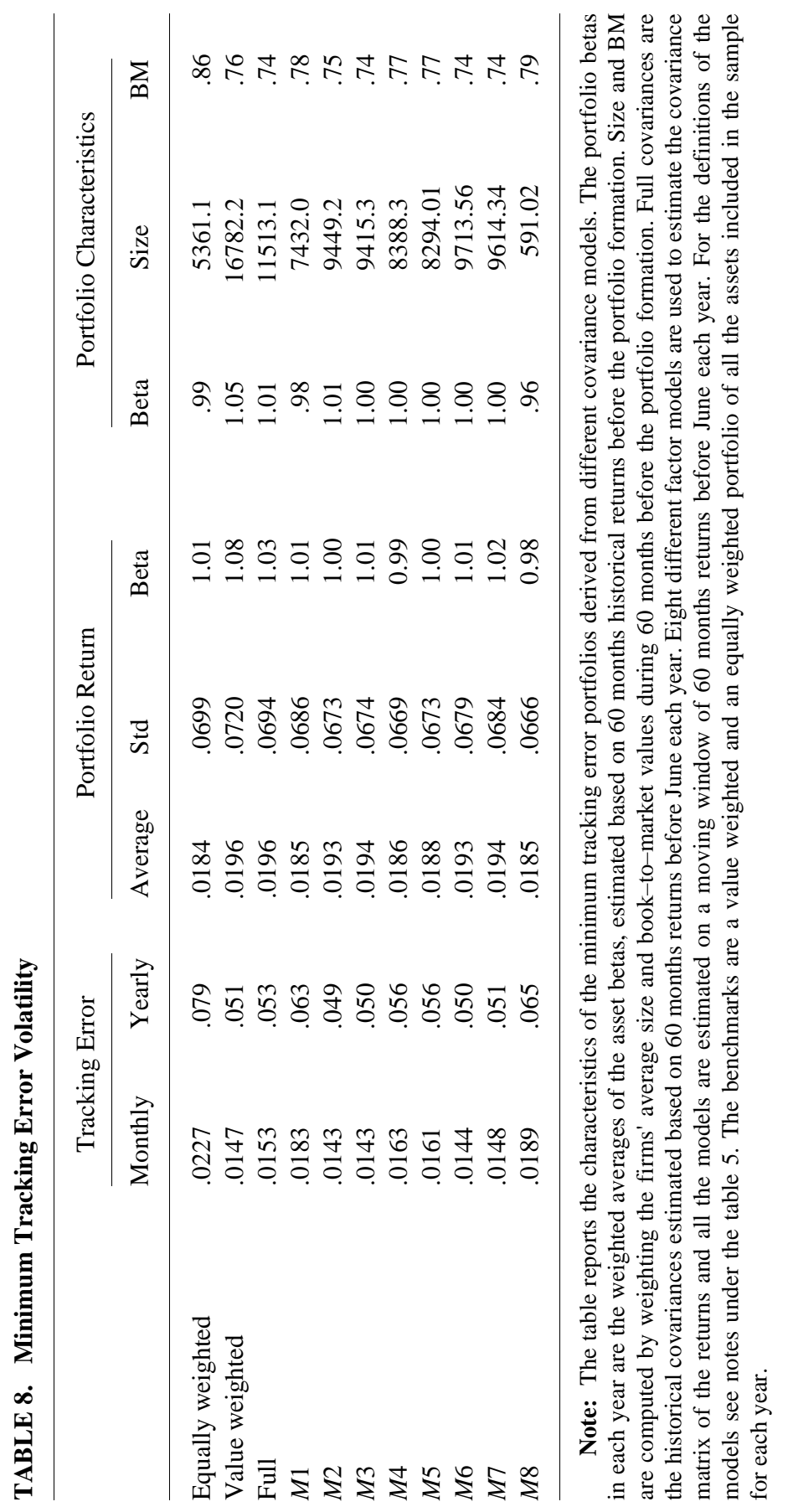


value weighted portfolio contains all assets with a life of at least six years and with historical weights. All models excluding Size and $B M$, including the market model $M 1$, perform poorly. That $M 1$ and $M 8$ are close to each other is not unexpected, since both models have no explanatory power for the excess returns and therefore their respective covariances are close to zero. Looking at the portfolio attributes all the models have market betas close to or equal to one. The best performing portfolios consist of large firms with low book-to-market values. Thus, both size and book-to-market are important attributes in forming a global minimum variance portfolio as well as in minimizing tracking error volatility, while the technical factors, which were important in the analysis of standard deviations, are now unimportant.

\section{Value at Risk}

For a portfolio manager it is interesting to test the capability of different factor models to predict possible future losses. One way to analyze this is to compute Value-at-Risk $(V a R)$ from the estimated covariance matrices of the factor models. Assuming that the portfolio value is equal to unity, $\operatorname{VaR}$ for a portfolio is defined as:

$$
\operatorname{VaR}=\mu-\sigma_{p} c_{\alpha},
$$

where $\mu$ is the expected return, $\sigma_{p}$ is the standard deviation of the portfolio and $c_{\alpha}$ is the critical value for the $\alpha \%$ one-sided confidence interval of a standard normal distribution. VaR is estimated for an equally weighted portfolio of all assets for which at least 60 months historical returns are available. Twelve months historical returns before the months under consideration are used to estimate $\mu{ }^{11}$ The covariance matrices implied by the different factor models and the full covariance matrix are used to estimate $\sigma_{p}$ :

$$
\sigma_{p}=\frac{1}{N^{2}} \imath^{\prime} V l,
$$

where $l$ is a vector of ones with a length equal to the number of assets, $N$. VaR is estimated for each month using an updated estimate of $V$ based on the preceding 60 months returns.

11. The estimated mean is not that important, since we are comparing the covariances across the models. 
TABLE 9. Outcomes Outside the Estimated Value-At-Risk

\begin{tabular}{lccc}
\hline & $99 \% C I$ & $95 \% C I$ & $90 \% C I$ \\
\hline Full & 2.00 & 6.67 & 10.00 \\
$M 1$ & 2.00 & 6.67 & 10.00 \\
$M 2$ & 2.00 & 6.67 & 10.00 \\
$M 3$ & 2.00 & 6.67 & 10.00 \\
$M 4$ & 2.00 & 6.67 & 10.00 \\
$M 5$ & 2.00 & 6.67 & 10.00 \\
$M 6$ & 2.00 & 6.67 & 10.00 \\
$M 7$ & 6.67 & 10.67 & 14.67 \\
$M 8$ & 18.00 & 24.00 & 27.33 \\
Expected portion & 1.00 & 5.00 & 10.00 \\
$Z$-statistics & & & \\
Full & & & .00 \\
$M 1$ & 1.23 & .94 & .00 \\
$M 2$ & 1.23 & .94 & .00 \\
$M 3$ & 1.23 & .94 & .00 \\
$M 4$ & 1.23 & .94 & .00 \\
$M 5$ & 1.23 & .94 & .00 \\
$M 6$ & 1.23 & .94 & .00 \\
$M 7$ & 1.23 & .94 & $1.91^{*}$ \\
$M 8$ & $6.98^{* * *}$ & $3.18^{* * *}$ & $7.08^{* *}$ \\
\hline & $20.93^{* *}$ & $10.68^{* * *}$ & \\
& & & 900
\end{tabular}

Note: The table shows the actual portion of the outcomes outside the boundary given by the estimated Value-at-Risk $(V a R)$ for different confidence levels $(C I)$. The table also reports the results of the test of equality between the expected proportion and the actual proportion. $\mathrm{VaR}$ is computed for an equally weighted portfolio of all assets for which at least 60 months historical return data is available. Mean returns are estimated with 12 months historical returns before the months under consideration. The portfolio variance is estimated using the covariance matrices implied by the different factor models and the full covariance matrix using 60 months historical returns. Eight different factor models are used to estimate the covariance matrix of the returns and all the models are estimated on a moving window of 60 months returns before June each year. For the definitions of the models see notes under the table 5. Z-statistics marked with one asterisk are significant at the $10 \%$ level and with two asterisks are significant at the $1 \%$ level. VaR is estimated for 150 months.

The purpose is to see if the ability of the commonly used market model to assess the maximum possible loss of an arbitrary portfolio can be increased by including an additional set of factors. The results in table 9 show that all factor models that include the market factor are identical. 
TABLE 10. Average Value-At-Risk

\begin{tabular}{llll}
\hline & $99 \% C I$ & $95 \% C I$ & $90 \% C I$ \\
\hline Full & -.157 & -.109 & -.083 \\
$M 1$ & -.152 & -.105 & -.080 \\
$M 2$ & -.157 & -.109 & -.083 \\
$M 3$ & -.157 & -.109 & -.083 \\
$M 4$ & -.155 & -.107 & -.081 \\
$M 5$ & -.154 & -.106 & -.081 \\
$M 6$ & -.157 & -.109 & -.083 \\
$M 7$ & -.108 & -.074 & -.056 \\
$M 8$ & -.054 & -.035 & -.026 \\
Empirical boundary & -.181 & -.108 & -.068 \\
Normal boundary & -.149 & -.102 & -.077 \\
\hline
\end{tabular}

Note: The table shows the average of the estimated $\operatorname{VaR}$ for different confidence levels $(C I)$. The table also reports the left-hand side boundaries given by the empirical distribution of the returns and by the normal distribution for different confidence levels. VaR is computed for an equally weighted portfolio of all assets for which at least 60 months historical return data is available. Mean and variance of the portfolio returns are used to estimate the boundaries for the normal distribution. Mean returns are estimated with 12 months historical returns before the months under consideration. The portfolio variance is estimated using the covariance matrices implied by the different factor models and the full covariance matrix using 60 months historical returns. Eight different factor models are used to estimate the covariance matrix of the returns and all the models are estimated on a moving window of 60 months returns before June each year. For the definitions of the models see notes under the table 5. VaR is estimated for 150 months.

Although the actual portions outside the boundaries of $1 \%$ and $5 \%$ are above the expected ones, the differences are not significantly different from zero. ${ }^{12}$ The expected portion outside the boundary is calculated from the empirical distribution while the $V a R$ of the factor models are constructed assuming normal distribution. The differences in proportions might be due to forecasting error in the covariance matrix and/or using the wrong distribution. To analyze this problem the article compares the empirical boundaries in table 10 with the boundaries constructed under the assumption of normality, where the latter is based on the average return and the sample standard deviation for the whole period. It is

12. Note that we have just 150 monthly observations and the expected number of observations outside the $1 \%$ boundary is 1.5 . 


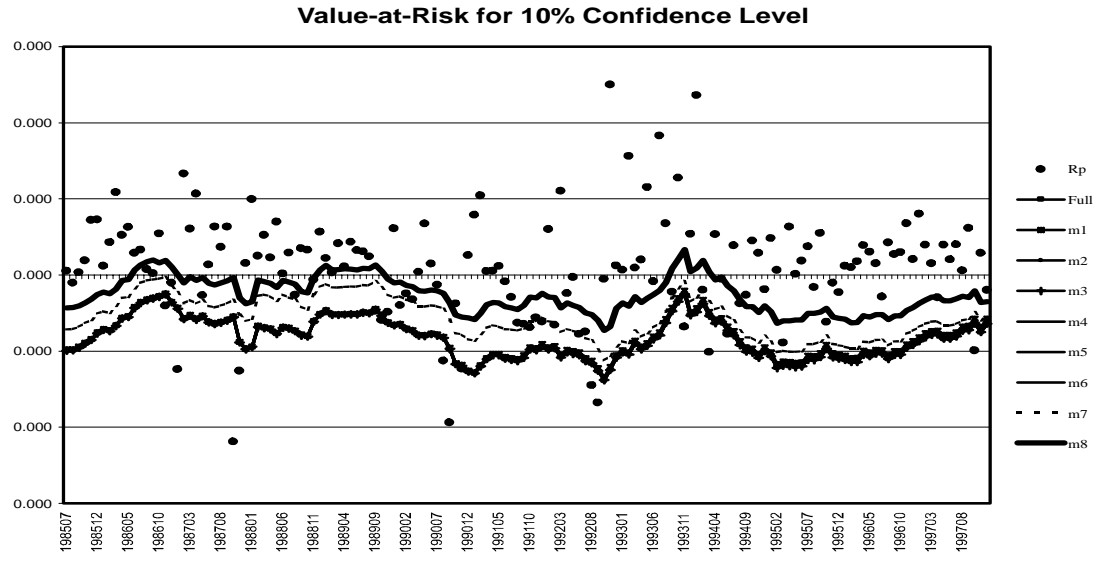

FIGURE 3.- Value-at-Risk for $10 \%$ confidence level estimated for an equally weighted portfolio of all assets for which at least 60 months historical return data is available. The portfolio variance is estimated using the covariance matrices implied by the different factor models and the full covariance matrix using 60 months historical returns. For the definitions of the models $M 1-M 8$ see notes under the table 5.

evident that the empirical distribution has more mass in the lower 1\%-tail than the normal distribution. At the same time, the differences between the average $V a R$ for the factor models and the normal boundaries are very small. Thus, the relatively poor results for the $99 \%$ confidence level probably stem from the assumption of normal distribution that is used in constructing VaR. The weak performances of the models $M 7$ and $M 8$ depend on their underestimation of the covariance elements that implies that the portfolio risks are underestimated and consequently the estimated losses are too small. Figure 3 shows the monthly variations in the $10 \%$ boundary, which are almost identical for all factor models that include the market. The results are similar to the exercise of predicting the covariance matrix, which is not surprising since for $\mathrm{VaR}$ it is also a question of predicting future covariance in order to find the proper distribution for an equally weighted portfolio.

The difference between the results of forecasting errors and $\mathrm{VaR}$ on the one hand and the results of risk minimization on the other hand has the following explanation: in the first case it is like an equally weighted portfolio, i.e. all elements in $V$ are equally important, but in the second 
case the risk reduction is obtained via large firms and firms with low book-to-market values, which implies that these firms receive high weights. Thus, in the latter case all elements in $V$ are not equally important, in fact, some elements are of no importance at all since the restriction of no short sales implies that several assets have zero weights (approximately $50 \%$ of the assets).

\section{Conclusions}

This article has investigated if a parsimonious set of factors is important determinants of common variation in returns. The specific object of analysis is the Swedish stock market for the period 1978 to 1997 . The choice of the factors has been inspired by the work of Chan, Karceski, and Lakonishok (1998), but the article has also included factors that should capture the fact that most Swedish firms are exposed to foreign competition and are active in several export markets. This makes the analysis interesting not only for other small open economies but also for sectors or firms in large economies that move on the world market. The analysis is split into two separate parts. The first part focuses on the standard deviations of the factor mimicking portfolios. The second part investigates if the different factor models are doing better than some benchmarks from the point of view of predicting and controlling risk.

In the first part the results show that the mimicking portfolios of most macro factors have standard deviations that are not significantly different from the standard deviation of the benchmark portfolio. Thus, from this perspective the macro factors are not important for explaining covariations among returns, which is a stronger result than the findings in Chan, Karceski, and Lakonishok (1998). The macro factor that represents foreign competition, the percentage change in the exchange rate SEK/USD $(D E X)$, is not important, which may appear a bit counterintuitive since very few Swedish firms have sheltered home markets. However, the most likely explanation is that the foreign influence is mediated via the world market portfolio. At the same time, the Swedish home market is an important factor and the world market does not subsume its volatility.

The second part first compares the general forecasting abilities of the factor models with the benchmarks. Several measures are used to 
compare the forecasted and the realized covariance matrices, and the most important is to estimate the magnitude of the forecast errors by looking at the mean absolute forecast errors. The main result is that the simplest model just including the market, i.e. the home market and the world market, is the best. The centrality of the market portfolio is similar to the results of Chan, Karceski, and Lakonishok (1999a).

To find the global minimum variance portfolio is a more risk management like exercise. The weights for this portfolio are constructed from the covariance matrices given by the different factor models and the full covariance matrix respectively. To evaluate the resulting portfolios the article uses their volatility of monthly returns. Unlike the previous tests the market model is not sufficient any longer and by adding Size and BM, which constitutes the Fama-French three-factor model, there is a relative reduction in the standard deviation of more than $4 \%$. A most interesting result is that the portfolios with low volatilities pick firms with low betas, low book-to-market values and sizes above the average. This is consistent with the interpretation of these attributes as risk factors. The dominance of the market factor makes it difficult to separate out the importance of the other factors. Therefore the article studies the tracking error volatility in relation to the value weighted market portfolio. Again the Fama-French three-factor model has the smallest tracking error and factor models including these three factors follow it. Thus, both size and book-to-market are important attributes for minimizing portfolio risk.

Finally the models are compared by using Value-at-Risk (VaR) where the portfolio variance is estimated by the factor models. The results show that all factor models that include the market factor are identical. These results are similar to the exercise of predicting the covariance matrix since both exercises give equal importance to all elements of the matrix. However, in order to find the global minimum variance portfolio it is most unlikely that this portfolio has equal weights.

The final view of the two methods for judging the importance of the different factors is that the standard deviations of the mimicking portfolios might be too generous for picking important factors while the predicted covariance matrices used in risk management applications, which are more import from an economic point of view, provide a finer separation. The article has two overall conclusions. The market, as represented by both the world market portfolio and the Swedish home 
market portfolio, is always of central importance. But in risk management practices the mimicking portfolios of size and book-tomarket are also essential.

\section{References}

Burmeister, E.; Roll, R.; and Ross, S. A. 1997. Using macroeconomic factors to control portfolio risk. Manuscript. BIRR Portfolio Analysis: www.birr.com.

Chan, L. K. C.; Karceski, J.; and Lakonishok, J. 1998. The risk and return from factors. Journal of Financial and Quantitative Analysis 33:159-188.

Chan, L. K. C.; Karceski, J.; and Lakonishok, J. 1999a. On portfolio optimization: Forecasting covariances and choosing the risk model. The Review of Financial Studies 12:937-974.

Chan, L. K. C.; Karceski, J.; and Lakonishok, J. 1999b. On mutual fund investment style. Working paper. NBER:w7215.

Chen, N. F.; Roll, R.; and Ross, S. A. 1986. Economic forces and the stock market. Journal of Business 59:383-403.

Cochrane, J. H. 2000. Asset Pricing. Princeton, New Jersey: Princeton University Press.

Daniel, K., and Titman, S. 1997. Evidence on the characteristics of crosssectional variation in stock returns. Journal of Finance 52:1-33.

Fama, E. F., and French, K. R. 1992. The cross-section of expected stock returns. Journal of Finance 47:427-465.

Fama, E. F., and French, K. R. 1993. Common risk factors in the returns on stocks and bonds. Journal of Financial Economics 33:3-56.

Jagannathan, R., and Ma, T. 2000. Three methods for improving the precision in covariance matrix estimation. Manuscript. Evanstone: Kellog Graduate School of Business, Northwestern University. 